\title{
On the reduction of chromate of lead
}

\section{R.F. Marchand}

To cite this article: R.F. Marchand (1840) On the reduction of chromate of lead, Philosophical Magazine Series 3, 16:105, 532-535, DOI: 10.1080/14786444008650085

To link to this article: http://dx.doi.org/10.1080/14786444008650085

册 Published online: 01 Jun 2009.

Submit your article to this journal 준

Џll Article views: 2

Q View related articles $₫$ 
almost invariably require to be tonched up afterwards, and therefore absolute identity is destroyed. The cost of their manufacture would be trifling, being merely the value of the zinc* dissolved in the battery, and a pound of zinc of the value of sixpence would produce a copper-plate weighing about two pounds; and I trust that copper will again, from its beauty, take the place of steel engravings.

So much for the precipitation of the copper; and the next thing to which $I$ have to direct your attention, is a mode of making a copperplate engraving without an engraving in the first instance. This is done by drawing upon a smooth piece of copper (such as a plate used for engraving) with any thick varnish or pigment insoluble in water, and then exposing the plate in the usual way to the influence of the current, when first copper will be thrown down upon the uncovered parts and will gradually grow over the drawing, and the electrotype when removed will be ready for printing. A practical difficulty, however, arises in the application of this in the arts, for unless very thick oil paint is used, sufficient depth is not obtained to hold theink. However, judging from the sharpness of the edges of the lines, I have but little doubt that this difficulty may be overcome by those who are accustomed to drawing; and it possesses, as an additional advantage to its cheapness, the valuable property of not requiring the artist to reverse the design. An opposite effect to this may be produced by placing a piece of copper similarly drawn upon at the oxygen end of the battery, when the metal will be acted upon, leaving a drawing in basso relievo.

Bank of England, April 21, 1840.

\section{ON THE REDUCTION OF CHROMATE OF LEAD. BY R. F. MAR-} CHAND.

The employment of chromate of lead, instead of oxide of copper, in organic analysis, is in many cases recommended by Richardson. It is preferable in the examination of substances containing chlorine, iodine, bromine, and sulphur, but particularly in the examination of the two latter. Erdman and I have frequently employed it with Hess's apparatus, and observed that the reduced chromate of lead will again absorb oxygen and might be then again employed. This circumstance induced me to make various experiments upon the reduction of this salt.

The chromate of lead used in these experiments was prepared by the precipitation of a solution of nitrate of lead with an excess of bichromate of potash, and afterwards carefully washing it : the salt was heated to dryness; it became of a dark red colour approaching cinnabar red; on cooling it returned to its former yellow colour provided it was not fused. If fused it turned to a dark brown colour, which on reducing to powder was of a brownish yellow colour. When the fused salt is quickly cooled by throwing it into cold water it becomes of a permanent red colour, giving also a red powder.

* The zinc in the fluid might be precipitated as a carbonate, for which there is great demand in the arts, and thereby the expense of the electrotype would be further diminished. 


\section{Marchand on the Reduction of Chromate of Lead.}

Many persons imagine that in organic analysis with chromate of lead it is necessary to use a very strong heat in order to perfect the operation. This is a mistake, for carbon as well as hydrogen very easily reduces the chromate. If however it is required to liberate oxygen, then the temperature must be very great, and the salt must be fused. This circumstance, as may be easily conceived, is inconvenient and liable to introduce error.

When chromate of lead is heated in a current of hydrogen gas, it commences to glow at a heat far below redness, and a quantity of water is formed. The yellow colour of the salt disappears; it becomes black, and very small metallic globules are disseminated through the mass.

3.049 grammes lost 0.307 gram. or 10.07 per cent. of oxygen; this loss may be increased by a continued and strong heat.

1.91 grammes lost in another experiment 0.224 gram., or 11.8 per cent. oxygen. At the commencement of the reduction of this purtion the temperature was kept moderate, by which it lost 0.2045 grm., or 10.7 per cent. Oxygen gas was then passed over it while in a heated state. At a low degree of heat, the mass burnt with great brilliancy, turned brown, at least partly so, which was very evident on cooling. It absorbed 0.133 grm. oxygen, which calculated for the original quantity $(1.91)$ amounted to 7 per cent.; a small quantity of water was formed during the operation, amounting, however, to but a few milligrammes. It would therefore appear that hydrogen was condensed in the pores of the reduced mass, but in a small quantity; heating in a stream of carbonic acid gas would have entirely driven it out. The oxidated quantity $1 \cdot 839$ grm. which had lost from the first 3.7 per cent. of oxygen, was again reduced in hydrogen gas, by which it lost $0.152 \mathrm{grm}$., this upon the whole quantity is equal to 8 per cent. Upon heating in oxygen gas the same appearances again took place, and the mass absorbed $0.128 \mathrm{grm}$., therefore, a similar quantity as before. A subsequent reduction at a very high temperature occasioned a loss of $0.128 \mathrm{grm}$. while a repeated oxidation only gave an increase of 0.119 . This was again driven out by hydrogen, but without any further decrease of oxygen.

If we examine these experiments, keeping in view the results, we shall find that $1.91 \mathrm{grm}$. lost $0.224 \mathrm{grm}$. equal to 11.8 per cent. while the last oxidation was only $1 \cdot 19$ grm. or 6.2 per cent. Chromate of lead contains 19.54 per cent. of oxygen, equal to four atoms, $\dddot{\mathrm{Cr}} \dot{\mathrm{Pb}}, 11 \cdot 8$ per cent. is equal to $2 \cdot 4$ atoms or nearly 8 ths of the whole amount of oxygen. This would be $12 \cdot 2$ per cent. The reduction, if complete, would convert all the oxide of lead into the metallic state and the chromic acid into the state of oxide of chrome.

\begin{tabular}{|c|c|}
\hline $\begin{array}{r}2 \mathrm{Cr}+6 \mathrm{O} \\
3 \mathrm{O}\end{array}$ & $\begin{array}{r}2 \mathrm{~Pb}+2 \mathrm{O} \\
2 \mathrm{O}\end{array}$ \\
\hline+30 & $2 \mathrm{~Pb}$. \\
\hline
\end{tabular}

By oxidation about half of the oxygen is recombined; this takes place the more readily when the metallic lead is in a finely divided 
state and not melted by too etrong a heat. It is not the lead alone, but also the oxide of chrome, which absorbs oxygen. If oxide of chrome alone be heated in oxygen gas, it is not converted into chromic acid; but this takes place, as is well known, if an alkali be present. I therefore consider that oxide of lead has the same effect in this respect as an alkali. In order to obtain an intimate mixture of oxide of chrome and oxide of lead, I endeavoured by means of heat so to decompose the chromate of lead, that all the chromic acid should be converted into oxide of chrome. The temperature must be very high for this purpose, and it requires a long time before any considerable quantity of oxygen cau be driven out of this salt. 1.409 gramme was fused in a very thin platina crucible by the strongest heat of a spirit-lamp before any appreciable loss took place. $0.057 \mathrm{grm}$. were then given off equal to 4 per cent. which is nearly ${ }_{1}^{3}$ ths of the whole quantity contained in it; this would be 3.9 per cent. It is therefore very probable that at first the chromate of lead is so decomposed that basic chromate of lead and oxide of chrome are formed.

$$
2\left(\mathrm{CrO}_{3} \mathrm{~Pb} \mathrm{O}\right)=\mathrm{CrO} \mathrm{O}_{3} \mathrm{~Pb}_{2} \mathrm{O}_{2}+\mathrm{CrO} 1 \frac{\mathrm{I}}{2}+\mathrm{O} 1 \frac{\mathrm{I}}{2} \text {. }
$$

The compound obtained in this manner $I$ considered very favourable for the conversion of chromic oxide into chromic acid. I heated it, and passed a stream of oxygen through it. However, to my great surprise, not the least alteration took place, and I found no increase in weight.

In the oxidation of the reduced salt, oxygen must have combined with the oxide of chrome, as 6.2 per cent. was in all absorbed, while the whole of the oxygen of the oxide of lead in the salt amounts only to 4.89 per cent.; and it is not at all likely that even the whole of this 4.89 per cent. was absorbed by the reduced lead, as it was for the most part fused into small globules, which must have very much prevented the action of the oxygen upon it.

I again fused 2.057 grammes of chromate of lead in an æther lamp supplied with oxygen : after a long-continued heat it lost 0.091 grm. or 4.4 per cent. The reduction was in this case carried on rather further than the conversion into basic chromate of lead and oxide of chrome. When, however, oxygen gas was passed over this compound very little of it was absorbed.

I at last prepared an intimate mixture of oxide of chrome and superoxide of lead; this was heated to redness and oxygen gas passed through it. This compound contained $0.445 \mathrm{grm}$. oxide of chrome. When the absorption had terminated, the increase of weight was found to be 0.066 grms. The colour was changed from green to brown. 0.455 grm. oxide of chrome contain 0.132 oxygen, therefore just double the quantity it had taken up. Therefore one atom of oxide of chrome upon heating with oxide of lead had combined with $1 \frac{1}{2}$ atom of oxygen.

This gives $2 \mathrm{Cr} 3 \mathrm{O}+2 \mathrm{PbO}+1 \frac{1}{2} \mathrm{O}$, or, $\mathrm{Cr} \mathrm{O}_{3} \mathrm{~Pb}_{2} \mathrm{O}_{2}+\mathrm{CrO} 1 \frac{\mathrm{I}}{2}$.

It is therefore the same compound which is formed when chromate of lead is fused by itself.

It follows from the foregoing experiments : 


\section{Portraits in Daguerreotype :-Meteorological Observations. 535}

That chromate of lead is very easily converted by means of carbon and hydrogen into a mixture of oxide of chrome and metallic lead.

This mixture by heating is in a state to combine with oxygen; and this combination takes place not only with the metallic lead, but also with the oxide of chrome.

By heat alone it is very difficult to deprive chromate of lead of oxygen. It is at first converted into a mixture of basic chromate of lead and oxide of chrome : in order to reduce all the chromic acid into oxide of chrome, an uncommonly highly temperature is required.

When a mixture of oxide of chrome and oxide of lead is heated, it is also converted into basic chromate of lead and oxide of lead.

It is therefore chromate of lead, which is often employed in organic analysis, from which this latter mixture is derived.--Journal für Praktische Chemie, No. 2. 1840.

\section{PORTRAITS IN DAGUERREOTYPE.}

Professor Draper, of the University of New York, informs us in a note dated March 31 st, that he has succeeded during the winter in procuring portraits by the Daguerreotype, and that they have all the beauty and softness of the most finished mezzotint engraving, and only require from 20 to 45 seconds for execution.

METEOROLOGICAL OBSERVATIONS FOR APRIL, 1840.

Chiswick.-A pril 1. Slight rain : cloudy. 2. Hazy : very fine. 3. Cold dry haze : frosty at night. 4-6. Very fine. 7. Fine: stormy showers at night. 8. Slight showers. 9. Cloudy and cold. 10-12. Very fine. 13-17. Fine but very dry. 18. Clear, hot and dry. 19. Hazy : very fine. 20. Very fine. 2123. Cloudy and fine. 24. Very fine. 25. Very hot, nearly cloudless, and excessively dry. 26, 27. Hot and dry. 28. Excessively hot for the period of the season, thermometer $81^{\circ}$ in the shade. 29,30. Very fine: hot and dry. This month is remarkable for the limited quantity of rain and for a high temperature; the latter being the consequence chietly of a powerful direct solar heat, which overcame likewise the counteracting effects of north and north-east winds, for they were in fact more prevalent than those from the opposite direction.

Boston.-A pril 1. Cloudy: rain P.M. 2. Rain. 3-5. Fine. 6. Cloudy. 7. Cloudy : stormy with rain R.M. 8. Cloudy : hail and rain P.3. 9-11. Fine. 12. Rain: rain early A.M. 19-19. Fine. 20-24. Cloudy. 25-29. Fine. 30. Cloudy.

Applegarth Manse, Dumfries-shire.-April 1. Mild day with a shower. 2. Keen and cold but dry. 8, 4. Dry and more temperate. 5. Fine day after a very slight shower. 6. Stormy day with showers, though slight. 7. Keen cold day. 8. More moderate. 9. Fine mild day. 10. The same: slightly moist and cloudy. 11. Drizzling all day, but very lightly. 12. Fine though cold: slight rain P. M. 13. Fine soft slight rain. 14. Charming spring day. 15. The same : with frost rime A.M. 16, 17. Fine but coldish: frost rime again. 18. Very fine warm day. 19. The same : white rime A.M. .20 . The same : slight showers P.M. 21. The same: gentle shower. 22. The same: moisture. 23. Dry but threatening. 24. The same: cleared up. 25-28. Beautiful day. 29. The same, but cloudy. 30 . The same : very warm.

Sun shone out 29 days. Rain, very slight, fell 6 days. Frost, rime 4 days.

Wind north 1 day. North-east $\frac{I}{2}$ day. East-north-east 2 days. East 3 days. East-south-east 1 day. South-east $\frac{1}{2}$ day. South-south-east 2 days. South 7 days. South-south-west $]$ day. South-west $7 \frac{7}{2}$ days. West-south-west 1 day. West $2 \frac{1}{2}$ days. North-west 1 day.

Calm 15 days. Moderate 8 days. Brisk 3 days. Strong breeze 3 days. Boisterous 1 day. 